\title{
TRANSLATION, ADAPTATION, AND PRELIMINARY VALIDATION OF DACAKIS AND DAVIES' "TRANSSEXUAL VOICE QUESTIONNAIRE (MALE TO FEMALE)" IN FRENCH
}

\author{
1Dominique Morsomme, ${ }^{2}$ Joana Revis, and 1Elisabeth Thomas \\ 1Department of Speech Language Therapy, Voice Unit, University of Liège, Liège, Belgium; \\ ${ }^{2}$ Laboratoire Parole et Langage - CNRS UMR 7309, Aix-en-Provence, Marseille, France.
}

\begin{abstract}
Summary: Transgender MtF people (trans women) consult otorhinolaryngologists and vocologists with the aim of feminizing their voice and being consistently perceived as women. Treatment of these trans women always begins with a vocal assessment that is relatively unspecific as it was originally constructed for individuals with dysphonia.

Objectives. This study examines the subjective portion of the assessment and specifically the self-assessment questionnaire. There is no French-language questionnaire designed to identify the issues facing people who want voice feminization and quantify the impact of their voice disorder on their daily lives. We present a translation and adaption into French of the questionnaire developed by Dacakis et al [6].

Methods. This work follows the World Health Organization recommendations [12] regarding translation. Thirty-six Belgian and French trans women took part in this study.

Results. The results show excellent repeatability and reliability, while the construct validity measures show that the items correlate with six areas of concern for trans women identified by Davies and Johnson [7] in a previous study. The domains are the following: effect of voice on ease of social interaction, effect of voice on emotions, relationship between voice and gender identity, effort and concentration required to produce voice, physical aspects of voice production, and pitch. Concurrent validity could not be measured owing to lack of sufficiently detailed stories.
\end{abstract}

Conclusion. The psychometric properties of the French version of the questionnaire are acceptable. The questionnaire can be used as is in daily clinical practice.

KEYWORDS: Voice feminization - Transgender male to female - Voice satisfaction - Voice questionnaire - Psychometric validation. 


\section{INTRODUCTION}

For the last decade or so, trans women have been consulting phoniatrics departments more frequently, seeking vocal techniques to feminize their voice, as taking hormones (estrogens and anti-androgens) plays no role in the acquisition of female voice patterns. ${ }^{1}$ Thus, these requests do not generally relate to a diagnosis of pathology but rather to a need to match the voice to the desired gender. Pitch, intonation contours, and timbre are important characteristics in the perception of gender. ${ }^{2}$ Incorrectly identified gender impairs trans women's quality of life. At present, the vocal assessments available are overly based on those for individuals with dysphonia; they are therefore of little use in formulating a treatment plan for trans women. The first step in treatment always consists in identifying the client's request. Although the Voice Handicap Index (VHI), for example, guides the vocologist in understanding a dysphonic person's complaint, allowing for therapeutic monitoring and effective treatment, this is not always true for transgender women. ${ }^{3}$ Self-evaluation scales play an important complementary role in carrying out a full vocal assessment and applying the resulting treatment. ${ }^{4}$ It is therefore imperative to appropriately identify the issues facing trans women. An additional problem is that no questionnaires focusing on transgender people exist in French.

In 2008, Pasricha et $\mathrm{al}^{5}$ published a questionnaire specifically developed for trans women, the Functional Communicative Satisfaction Questionnaire. However, this questionnaire measures primarily pragmatic and communicative capacities and does not provide specific information on trans women's satisfaction with their voices. In 2006, Davies and Goldberg developed the Transgender Self-Evaluation questionnaire (TSEQ), based on the VHI. The final version of the TSEQ contained no more than one third of the original items of the VHI and was tested on only 14 trans women. To remedy the TSEQ's psychometric weaknesses, Dacakis and Douglas, two Australian vocologists, created the Transsexual Voice Questionnaire for Male-to-Female (TVQ ${ }^{\mathrm{MtF}}$ ) in 2012. They reviewed all the aspects of the questionnaire with two trans women. The first version of the TVQ ${ }^{\mathrm{MtF}} 6$ was published in 2013 based on the responses of 35 trans women (29 Australian and 6 Canadian). The questionnaire takes the form of a self-report measure of vocal functioning and measures the impact of voice on the everyday lives of trans women. Its objective was to determine their daily satisfaction with their voice in order to better establish the therapeutic goals of the treatment and measure its efficacy. ${ }^{6}$ The TVQMtF includes 30 items. The rating scale has four levels ( 1 = never or rarely, $2=$ sometimes, $3=$ often, $4=$ usually or always). The minimum score is 30 and the maximum is 120 . When tested, the psychometric properties were satisfactory and the questionnaire had good internal consistency (Cronbach $\alpha: 0.974$ ) and reliability (intraclass correlation coefficient [ICC]: 0.979). Nevertheless, the authors expressed reservations regarding the small number of participants, adding that the majority of participants came from Australia and had undergone feminization sessions. They clarified that the study was limited to the examination of reliability and indicated that their results could not be generalized to the wider population of trans women.

Therefore, in 2015, in a second step, Davies and Johnston ${ }^{7}$ studied the validity of the tool, testing its construct and concurrent validity. Their main research question was: To what extent does the $\mathrm{TVQ}^{\mathrm{MtF}}$ provide a valid representation of trans women's concerns about their voices? In other words, they looked at whether the questionnaire measured what it was supposed to measure. To do this, the authors recruited five trans women. Each of them was interviewed for 1 hour. The first 30 minutes were devoted to the story of their experience, their vocal concerns, and the impact of their transition on their daily lives. In the last 30 minutes, they filled in the TVQMtF. 
From the first part of the interview, authors collected 780 ideas, of which 240 were related to the voice. Six domains were identified on the basis of the interviews. The authors then analyzed the questionnaire's construct and concurrent validity. Regarding construct validity, 29 of the 30 items clearly address the concerns of trans women, which shows their relevance, although the authors note that $24 \%$ of the voice-related ideas gathered from participants are not covered in the questionnaire. As for concurrent validity, the questionnaire correctly explores the concerns of trans women. The topics covered in the questionnaire correlate with the content of interviews. Thus, these results support the validity of the TVQ ${ }^{\mathrm{MtF}}$.

In 2016, Dacakis et $\mathrm{al}^{8}$ tested their questionnaire on 53 transgender women, 26 of whom had received gender reassignment surgery. Transgender women who had received this surgery reported on the TVQ ${ }^{\mathrm{MtF}}$ that their voice had a less negative impact on their gender identity than those who had not. However, the authors added that they did not observe any difference between the two groups in terms of vocal functioning concerns and voice-related activity and participation issues. Byrne [in 8] suggested an explanation that the authors cite. In pretransition phase, trans women are focused on their transition; they are still living as men and hiding their true identity. During the transition phase, they start to construct their identity as women; in the post-transition phase, they accept the limits of their voice. Their voice is not the only characteristic allowing for their identification as women, and so they are less dependent on it. The study shows that TVQ ${ }^{\mathrm{MtF}}$ scores differentiate between transgender women who have received gender reassignment surgery and those who have not.

At present, this tool is the most complete and appropriate one for evaluating the daily satisfaction that people seeking voice feminization do or do not experience. It has already been translated into eight languages (Swedish, German, Portuguese, Croatian, Danish, Finnish, Dutch, Hebrew, and Spanish). ${ }^{9}$ It was therefore important to provide a tool for clinicians who care for and support trans women in French as well. We should add that in Belgium, since September 1, 2013, voice therapy sessions for feminization are reimbursed if the following conditions are met: provide a diagnosis of gender dysphoria signed by a psychiatrist, have a fundamental frequency that is inappropriate for the desired gender, and have a score on the VHI created by Jacob-son et $\mathrm{al}^{10}$ of greater than 20." Because the VHI was developed for people with dysphonia, it does not allow transgender people to rate their voice satisfaction and quality of daily life. They rarely score higher than 20 because they do not have a dysphonic voice. Translating, adapting, and validating the TVQ ${ }^{\mathrm{MtF}}$ in French was therefore a useful and necessary task. This work was approved by Dacakis and Davies' team.

\section{METHODS}

\section{TRANSLATION PROCEDURE}

To translate the questionnaire, we followed the World Health Organization's guidelines, ${ }^{12}$ which are organized in seven steps as shown in Figure 1. We first contacted the authors of the TVQ ${ }^{\mathrm{MtF}} 6$ to get their approval. They agreed with our proposal in writing, considering that our translation would become the official version in French.

To be translated into another language, the questionnaire must, above all, be adapted to that language. This means a simple literal translation is not sufficient. All items have to be understood in the same way across cultures and different countries. The goal is not to obtain a 
perfect translation but to obtain a questionnaire that evaluates the same thing despite differences between cultures in terms of vocabulary, definitions, and expressions. The first person who takes responsibility for translating the questionnaire must be familiar with the subject matter and that person's mother tongue must be the target language of the tool (in our case, French). The wording should be clear and concise.

In our case, Thomas (third author) executed the first step in the translation. Once we had this initial translation, we consulted a group of persons including the original translator, professionals in the voice field, and professionals with experience in tool development. This group evaluated the first translation's quality and enhanced it, if necessary. For example, item 14 was initially written as Ma voix sonne comme si elle était artificielle ("My voice sounds as if it was artificial.") ; after discussion this item was changed to Le son de ma voix est artificiel ("My voice sounds artificial."). The new formulation appears more concise, clear, and easy to understand.

Respecting the guidelines concerning the second step, the first translation was submitted to Morsomme and Verduyckt, researchers and vocologists in the field of voice feminization. Four items were changed (14. Le son de ma voix est artificiel. ["My voice sounds artificial."] 16. Cela me frustre d'essayer de modifier ma voix. ["I feel frustrated with trying to change my voice."] 18. Quand je n'y prête pas attention, la hauteur de ma voix devient plus grave. ["When I am not paying attention my pitch goes down."] 26. Je suis constamment préoccupée par la manière dont les autres perçoivent ma voix. ["I feel self-conscious about how strangers perceive my voice."]). Then, another bilingual person, totally unfamiliar with the voice field, retranslated the French questionnaire into English. Thus, we obtained two English translations that we had the expert group compare. This second translation took cross-cultural differences into account. Together with this bilingual person, the expert group re-examined the translations to reach a new consensus. Once again, in this retranslation, it was not linguistic equivalence that prevailed but conceptual equivalence.

We then sent the questionnaire to Alice Cameron, a native speaker of British English. For 16 years, since obtaining her master's degree in translation, she has worked as a freelance translator for various agencies and public organizations. Ms. Cameron was totally unfamiliar with the field of voice and she retranslated the questionnaire into its original language. This work was compared to the items in Dacakis et al's questionnaire6 by Morsomme (first author) and Revis (second author). Revis is also a speech therapist, vocologist, and researcher in linguistics. In her clinical practice, she works with women who wish to feminize their voice. For this step, Dacakis and Davies gave us advice, telling us of problems that other authors had experienced in other languages. For example, they clarified certain terms and expressions so we could better appreciate their meaning and scope. This happened with item 13, where the expression parler en public ("speak in public") does not mean to give a lecture or a presentation but to talk in front of other people during informal conversations; with item 25, where the expression sortir de chez soi ("go out") does not refer to being or not being open to contact with others (cf. the English outgoing); and item 28 with the word distresses, which was translated to affecte ("affects, moves") rather than bouleverse ("upsets"). Afterward, the majority of items were modified, following discussions with the group of experts, Morsomme and Revis. These changes did not concern sentence syntax but certain words that were seen as overly complex. For example, hauteur ("pitch") was replaced by ton de ma voix ("tone of my voice"), pas fiable ("unreliable") was replaced by imprévisible ("unpredictable"), and moins encline ("less inclined to") was replaced by ai moins envie ("want to less"). This step enabled us to simplify the items and make them more understandable for everyone. The new version was submitted to Ms. 
Cameron, who translated it into English. The two English versions were again compared and approved by the expert group (Morsomme and Revis).

When all the persons involved in the translation agree on a final translation, it is essential to pretest it on the target population (in our case, trans women). We organized a debriefing after each participant completed the questionnaire to collect her impressions and see how she had answered it. The pretest was done with four transgender women, whom we then retained in the sample, given the small number of subjects included in our study.

The final version of the questionnaire was the outcome of all these steps. The flowchart in Figure 1 illustrates the entire translation process.

FIGURE 1. Translation process. SLT, Speech Language Therapist; TVQ ${ }^{M t F}$, Transsexual Voice Questionnaire for Male-to-Female.

\begin{tabular}{|c|c|c|c|c|c|c|}
\hline $\begin{array}{c}\text { TVQ } \\
\text { Dacakis et al [6] }\end{array}$ & $1^{\text {st }}$ French version & $2^{\text {nd }}$ French version & English version & $3^{\text {rd }}$ French version & $2^{\text {nd }}$ English version & \\
\hline $\begin{array}{l}\text { First translation from } \\
\text { English to French } \\
\text { Thomas }\end{array}$ & $\begin{array}{l}\text { Discussion with SLT } \\
\text { vocologists } \\
\text { Adaptation according } \\
\text { to Thomas, Morsomme, } \\
\text { Verduyckt, Revis }\end{array}$ & $\begin{array}{l}\text { Translation from } \\
\text { French to English } \\
\text { Native speaker of } \\
\text { British English - not } \\
\text { specialist in the voice } \\
\text { field, Cameron }\end{array}$ & $\begin{array}{l}\text { Comparison of this } \\
\text { version and the } \\
\text { orlginal and } \\
\text { discussion of } \\
\text { conceptual } \\
\text { equivalence }\end{array}$ & $\begin{array}{l}\text { Discussion of } \\
\text { conceptual } \\
\text { equlvalence } \\
\text { Vocologists specializing } \\
\text { in the voice field- } \\
\text { Thomas, Morsomme }\end{array}$ & $\begin{array}{l}\text { Discussion of } \\
\text { conceptual } \\
\text { equivalence } \\
\text { Vocologists specializing } \\
\text { in the voice field- } \\
\text { Thomas, Morsomme, }\end{array}$ & $\begin{array}{c}\text { Final } \\
\text { French } \\
\text { version }\end{array}$ \\
\hline & & & $\begin{array}{l}\text { Translation from } \\
\text { English to French and } \\
\text { modification of Iterns } \\
\text { in the 2nd French } \\
\text { version } \\
\text { Vocologists specializing } \\
\text { in the voice field - } \\
\text { Thomas, Morsomme, } \\
\text { Revis, Verduyckt }\end{array}$ & $\begin{array}{l}\text { Revis, Verduyckt } \\
\text { Translation from } \\
\text { French to English } \\
\text { Native speaker of } \\
\text { British English - } \\
\text { Cameron. }\end{array}$ & $\begin{array}{l}\text { Revis, Verduyckt } \\
\text { Total agreement on } \\
\text { the new tool } \\
\text { Pretesting of the tool } \\
\text { on } 10 \text { trans women }\end{array}$ & \\
\hline
\end{tabular}

\section{SUBJECTS}

Ethical approval was obtained from the Ethics Committee of the Department of Psychology, Speech and Language Therapy, and Education at the University of Liège.

The participants were recruited through various lesbian, gay, bisexual, and transgender (LGBT) movements and associations (https://www.arcenciel-wallonie.be, http://federation-lgbt.org/) in Belgium and France, as well as through speech therapists and speech language pathologists. Most participants contacted us by telephone and e-mail once they had found out about the study. The inclusion criteria for the study were that participants had to have started hormone therapy, be native speakers of French, and be in or after the real-life test period. During the 2-year waiting period for gender reassignment, trans women have to engage in the real-life test. This consists of adopting the appearance and social codes of the feminine gender in daily life. This step is crucial for determining the possible changes as a trans woman and is essential before an irrevocable decision is made.

The experimental sample included 36 participants. The mean age of the group was 43.7 years ( $S D=15.89$ ). The question that determined if the participant suffered from voice complaints or disease affecting the voice is: Are you consulting or have you thought about consulting a doctor for voice problems (other than the feminization request)? If yes, when and why? None of the participants suffered from dysphonia. Three of them stated that they had had phonosurgery as part of their feminization process. 


\section{QUESTIONNAIRE}

The questionnaire was posted online to make it easier to transmit and complete. To do this, we used the online survey management system of the University of Liège Faculty of Psychology, Speech and Language Therapy, and Education decentralized IT unit. Participants were sent a link by e-mail. Once they clicked on the link, they arrived at an introductory page that included a summary of the research, the contact information for the speech therapy unit, and the informed consent form. By taking the further steps required to access the questionnaire, they automatically "signed" the consent form. On page 2, participants completed a case history form (date of birth, date they started taking hormones, native language, profession, leisure activities such as singing or theater, tobacco consumption, whether or not they had received voice therapy, whether or not they had seen an otorhinolaryngologist). On page 3 , they answered the following question: Can you tell us about your experiences with your voice in your daily life? You can also describe what you think when people talk about your voice and any voice-related concerns you may have. Page 4 presented the 30 items of the questionnaire. On page 5, participants were thanked and informed of the retest procedure. A new link to the questionnaire was sent 7 days after each participant first completed the questionnaire. To encourage participants to answer again, we also sent them a text message. They answered the questionnaire a second time within 7-14 days. ${ }^{13}$ The retest procedure was identical to the original test, except on page 3 , where this step ended with warm thanks.

After the two questionnaire sessions, the data were anonymized and stored in an Excel file.

\section{HYPOTHESES}

We formulated hypotheses concerning the questionnaire's repeatability, reliability, and validity. As we also collected information with the case history questionnaire, we added two hypotheses regarding therapeutic treatment and the potential effect of the participants' country of origin (Belgium vs. France).

Regarding repeatability, we postulated that test-retest reliability measures for the $\mathrm{TVQ}^{\mathrm{MtF}}$ in French would be similar to those obtained for the original English version. We kept in mind the fact that, as in the Dacakis et al study, our internal consistency and reliability are based on a small sample. However, we consider that 36 participants represent a moderately large group for this population. For construct validity, we hypothesized that the measures for our French version of the TVQ ${ }^{\mathrm{MtF}}$ would be similar to those obtained for the English original. As for concurrent validity, we hypothesized that the women's vocal experiences would cover the six content themes underlying the TVQ ${ }^{\mathrm{MtF}}$ items: (1) effect of voice on ease of social interaction, (2) effect of voice on emotions, (3) relationship between voice and gender identity, (4) effort and concentration required to produce voice, (5) physical aspects of voice production, and (6) pitch. The following two hypotheses concerning these external variables were formulated: participants who had received voice therapy sessions would obtain lower $\mathrm{TVQ}^{\mathrm{MtF}}$ scores than the others. As both Belgian and French participants were French native speakers, we expected that nationality will not impact the results. Note that a lower score means fewer complaints, and a higher one means more complaints. The authors consider that there are at least some complaints from the moment a trans 
woman decides to fill in the questionnaire. Even if the participant chooses the answer 1 (never or rarely), that means that for all the items rated as 1 , the situation could happen occasionally.

\section{ANALYSIS AND STATISTICS}

Statistica softwarel Win (version 12, StatSoft Inc., Tulsa, OK) was used for statistical analysis.

The Shapiro-Wilk test was used to verify the normality of the distribution of each of our variables. Then Levene's test and Brown-Forsythe's modification of this test were carried out to verify the equality of variances in the different groups. These tests allowed us to verify the equality of the variances and choose the type of analysis of variance (ANOVA) to apply. Based on our hypothesis, the following statistical analyses were performed.

The internal consistency of the questionnaire was analyzed via Cronbach alpha. The test-retest reliability was tested by the ICC.

Construct validity - the relationship between the domains established by the authors of the original $\mathrm{TVQ}^{\mathrm{MtF}}$ and the items of the translated questionnaire-was tested first by classifying the participants' written ideas into the six domains underlying the TVQ ${ }^{\mathrm{MtF}}$ plus a seventh domain labeled "other." A chi-square test made it possible to observe the relationship between participants' written ideas and the fact that the 30 items in the $\mathrm{TVQ}^{\mathrm{MtF}}$ expressed their ideas. Next, we analyzed the correlation between the distribution of ideas by domains in the written narratives and their distribution within the items of the questionnaire using Spearman rank test. Friedman ANOVA allowed us to test the hypothesis that there might be a difference in the importance of the domains covered. And finally, the level of agreement among participants regarding the evaluations of the different domains was calculated using Kendall concordance coefficient.

Concurrent validity was analyzed by comparing the scores obtained on the French $\mathrm{TVQ}^{\mathrm{MtF}}$ to an external criterion, namely, the participants' spontaneous narratives. The mean $\mathrm{TVQ}^{\mathrm{MtF}}$ score per participant was compared to the mean score for all responses by domain. The scores were ranked and the ranks compared using Spearman correlation coefficient.

To investigate the hypothesis concerning therapeutic follow-up, we distinguished between three groups: participants who had not received vocal feminization sessions, participants who had received vocal feminization sessions in the past, and participants who were still receiving voice sessions during the study period. We performed a oneway ANOVA to determine whether or not there is a difference between the three groups. To better understand the difference between the three groups' responses, we applied a post hoc test.

Finally, to examine the hypothesis concerning the participants' country of origin (Belgium vs. France), we used a Student t test. 
We considered our results to be statistically significant when the two-sided $P$ value was lower than 0.05 (uncertainty level 5\%).

\section{RESULTS}

First, we checked the normality of the distribution of each of the variables using the ShapiroWilk test. Almost all of our data were normally distributed. Only items taken in isolation were not normally distributed (Table 1).

TABLE 1. Normality of the Data-Shapiro-Wilk Test

\begin{tabular}{|c|c|c|c|c|}
\hline & $\mathrm{N}$ & First Test & Post Test & Normality* \\
\hline Total scores for participants & $\mathrm{N}=36$ & $\mathrm{~W}=0.96(P=0.33051)$ & $\mathrm{W}=0.95(P=0.12220)$ & $P>.05$ \\
\hline Total scores for items & $\mathrm{N}=30$ & $\mathrm{~W}=0.98(P=0.83972)$ & $\mathrm{W}=0.96(P=0.52201)$ & $P>.05$ \\
\hline Scores on item 1 & $\mathrm{~N}=36$ & $\mathrm{~W}=0.87(P=0.0007)$ & $\mathrm{W}=0.87(\mathrm{P}=0.0007)$ & ns \\
\hline Scores on item 2 & $\mathrm{~N}=36$ & $\mathrm{~W}=0.81(P=0.0007)$ & $\mathrm{W}=0.85(P=0.0007)$ & ns \\
\hline Scores on item 3 & $\mathrm{~N}=36$ & $\mathrm{~W}=0.84(P=0.0007)$ & $\mathrm{W}=0.85(P=0.0007)$ & ns \\
\hline Scores on item 4 & $\mathrm{~N}=36$ & $\mathrm{~W}=0.84(P=0.0007)$ & $\mathrm{W}=0.85(P=0.0007)$ & ns \\
\hline Scores on item 5 & $N=36$ & $\mathrm{~W}=0.86(P=0.0007)$ & $\mathrm{W}=0.85(P=0.0007)$ & ns \\
\hline Scores on item 6 & $\mathrm{~N}=36$ & $\mathrm{~W}=0.84(P=0.0007)$ & $\mathrm{W}=0.73(P=0.0007)$ & ns \\
\hline Scores on item 7 & $\mathrm{~N}=36$ & $\mathrm{~W}=0.75(P=0.0007)$ & $\mathrm{W}=0.78(P=0.0007)$ & ns \\
\hline Scores on item 8 & $\mathrm{~N}=36$ & $\mathrm{~W}=0.81(P=0.0007)$ & $\mathrm{W}=0.81(P=0.0007)$ & ns \\
\hline Scores on item 9 & $\mathrm{~N}=36$ & $\mathrm{~W}=0.83(P=0.0007)$ & $\mathrm{W}=0.83(P=0.0007)$ & ns \\
\hline Scores on item 10 & $\mathrm{~N}=36$ & $\mathrm{~W}=0.84(P=0.0007)$ & $\mathrm{W}=0.81(P=0.0007)$ & ns \\
\hline Scores on item 11 & $\mathrm{~N}=36$ & $\mathrm{~W}=0.87(P=0.0007)$ & $\mathrm{W}=0.87(P=0.0007)$ & ns \\
\hline Scores on item 12 & $\mathrm{~N}=36$ & $\mathrm{~W}=0.62(P=0.0007)$ & $\mathrm{W}=0.70(P=0.0007)$ & ns \\
\hline Scores on item 13 & $\mathrm{~N}=36$ & $\mathrm{~W}=0.77(P=0.0007)$ & $\mathrm{W}=0.76(P=0.0007)$ & ns \\
\hline Scores on item 14 & $\mathrm{~N}=36$ & $\mathrm{~W}=0.65(P=0.0007)$ & $\mathrm{W}=0.74(P=0.0007)$ & ns \\
\hline Scores on item 15 & $\mathrm{~N}=36$ & $\mathrm{~W}=0.80(P=0.0007)$ & $\mathrm{W}=0.80(P=0.0007)$ & ns \\
\hline Scores on item 16 & $\mathrm{~N}=36$ & $\mathrm{~W}=0.80(P=0.0007)$ & $\mathrm{W}=0.83(P=0.0007)$ & ns \\
\hline Scores on item 17 & $\mathrm{~N}=36$ & $\mathrm{~W}=0.74(P=0.0007)$ & $\mathrm{W}=0.75(P=0.0007)$ & ns \\
\hline Scores on item 18 & $\mathrm{~N}=36$ & $\mathrm{~W}=0.84(P=0.0007)$ & $\mathrm{W}=0.86(P=0.0007)$ & ns \\
\hline Scores on item 19 & $\mathrm{~N}=36$ & $\mathrm{~W}=0.83(P=0.0007)$ & $\mathrm{W}=0.78(P=0.0007)$ & ns \\
\hline Scores on item 20 & $\mathrm{~N}=36$ & $\mathrm{~W}=0.84(P=0.0007)$ & $\mathrm{W}=0.83(P=0.0007)$ & ns \\
\hline Scores on item 21 & $\mathrm{~N}=36$ & $\mathrm{~W}=0.82(P=0.0007)$ & $\mathrm{W}=0.85(P=0.0007)$ & ns \\
\hline Scores on item 22 & $\mathrm{~N}=36$ & $\mathrm{~W}=0.84(P=0.0007)$ & $\mathrm{W}=0.84(P=0.0007)$ & ns \\
\hline Scores on item 23 & $\mathrm{~N}=36$ & $\mathrm{~W}=0.70(P=0.0007)$ & $\mathrm{W}=0.69(P=0.0007)$ & ns \\
\hline Scores on item 24 & $\mathrm{~N}=36$ & $\mathrm{~W}=0.84(P=0.0007)$ & $\mathrm{W}=0.86(P=0.0007)$ & ns \\
\hline
\end{tabular}


Scores on item 25

Scores on item 26

Scores on item 27

Scores on item 28

Scores on item 29

Scores on item 30

Total scores for domains

$\%$ of Ideas per domain

Scores for participants who

had completed therapy

Scores for participants $\mathrm{N}=18$ currently receiving therapy

Scores for participants not $\mathrm{N}=10$ taking therapy

$$
\begin{array}{cccc}
\mathrm{N}=36 & \mathrm{~W}=0.71(P=0.0007) & \mathrm{W}=0.70(P=0.0007) & \mathrm{ns} \\
\mathrm{N}=36 & \mathrm{~W}=0.82(P=0.0007) & \mathrm{W}=0.80(P=0.0007) & \mathrm{ns} \\
\mathrm{N}=36 & \mathrm{~W}=0.85(P=0.0007) & \mathrm{W}=0.84(P=0.0007) & \mathrm{ns} \\
\mathrm{N}=36 & \mathrm{~W}=0.80(P=0.0007) & \mathrm{W}=0.81(P=0.0007) & \mathrm{ns} \\
\mathrm{N}=36 & \mathrm{~W}=0.84(P=0.0007) & \mathrm{W}=0.87(P=0.0007) & \mathrm{ns} \\
\mathrm{N}=36 & \mathrm{~W}=0.70(P=0.0007) & \mathrm{W}=0.78(P=0.0007) & \mathrm{ns} \\
\mathrm{N}=7 & \mathrm{~W}=0.91(P=0.42007) & \mathrm{W}=0.91(P=0.80) & \mathrm{P}>0.05 \\
\mathrm{~N}=7 & \mathrm{~W}=0.89(P=0.30562) & \mathrm{P}>0.05 \\
\mathrm{~N}=8 & \mathrm{~W}=0.80(P=0.03127) & \mathrm{ns} \\
\mathrm{N}=18 & \mathrm{~W}=0.69496(P=0.0000) & \mathrm{ns} \\
\mathrm{N}=10 & \mathrm{~W}=0.58201(P=0.0000) & \mathrm{ns}
\end{array}
$$

\begin{tabular}{|c|c|c|c|c|c|}
\hline French TVQ Items-Test & Mean & SD & M in/Max & Med & Mode $(\%)^{*}$ \\
\hline $\begin{array}{l}\text { 15. Je dois me concentrer pour que ma voix soit comme je veux. (I } \\
\text { have to concentrate to make my voice sound the way I want it to } \\
\text { sound.) }\end{array}$ & 2.89 & 1.14 & $1-4$ & 2 & $4(41.66)$ \\
\hline $\begin{array}{l}\text { 4. Le ton de ma voix parlée est trop grave. (The pitch of my } \\
\text { speaking voice is too low.) }\end{array}$ & 2.72 & 0.88 & $1-4$ & 2 & $3(41.66)$ \\
\hline $\begin{array}{l}\text { 18. Quand je n'y prête pas attention, la hauteur de ma voix } \\
\text { devient plus grave. (When I am not paying attention my pitch goes } \\
\text { down.) }\end{array}$ & 2.67 & 1.01 & $1-4$ & 2.5 & $2(38.88)$ \\
\hline $\begin{array}{l}\text { 28. Cela m'affecte profondément d'être perçue comme un homme } \\
\text { à cause de ma voix. (It distresses me when I'm perceived as a man } \\
\text { because of my voice.) }\end{array}$ & 2.67 & 1.22 & $1-4$ & 3 & $4(36.11)$ \\
\hline $\begin{array}{l}\text { 20. Ma voix ne reflète pas mon apparence physique. (My voice } \\
\text { does not match my physical appearance.) }\end{array}$ & 2.53 & 1.13 & $1-4$ & 2 & 3 (27.77) \\
\hline $\begin{array}{l}\text { 3. Je me sens moins féminine à cause de ma voix. (My voice makes } \\
\text { me feel less feminine than I would like.) }\end{array}$ & 2.50 & 1.13 & $1-4$ & 1.5 & $3(25.00)$ \\
\hline 11. La hauteur de ma voix ne varie pas assez quand je parle. ( & 2.44 & 0.97 & $1-4$ & 2 & $3(36.11)$ \\
\hline
\end{tabular}

* Threshold $(\mathrm{P}=0.05)$.

\section{DESCRIPTIVE DATA}

Table 2 shows the mean score obtained for each item of the French-language TVQ ${ }^{\mathrm{MtF}}$. The items are ranked from most chosen (item 15) to least chosen (item 14). Thus, items scored 3 and 4 occupy the first eight places in the ranking. Items scored 1 and 2 are located at the bottom of the list. This table covers the results for the first test; the descriptive data for the retest are similar to those for the test. The mean total score on the test was 65.44 (min: 31; max: 117; SD: 22.40), whereas the mean total score on the retest was 66.58 (min: 30; max: 115; SD: 23.40).

TABLE 2. Descriptive Statistics for the Test; Scores Obtained on the French-language TVQ ${ }^{M t F}$ 
24. J'ai l'impression que ma voix ne reflète pas qui je suis vraiment (I feel my voice does not reflect the "true me. ")

19. Mon rire sonne comme celui d'un homme. (When I laugh I sound like a man.)

1. On m'entend difficilement dans un milieu bruyant. (People have difficulty hearing me in a noisy room.)

29. L'étendue de ma voix parlée est limitée. (The pitch range of my speaking voice is restricted.)

5. La hauteur de ma voix est imprévisible. (The pitch of my voice is unreliable.)

21. Je fais beaucoup d'efforts pour parler. (I use a great deal of effort to produce my voice.)

2. Je suis nerveuse quand je sais que je dois utiliser ma voix. (I feel anxious when I know I have to use my voice.)

10. Je suis difficilement identifiée comme femme à cause de ma voix. (My voice makes it hard for me to be identified as a woman.)

26. Je suis fortement embarrassée par la manière dont les autres perçoivent ma voix. ( feel self-conscious about how strangers perceive my voice.)

7. J'évite de téléphoner à cause de ma voix. (I avoid using the phone because of my voice.)

22. Ma voix se fatigue rapidement. (My voice gets tired quickly.)

16. Cela me frustre de devoir essayer de modifier ma voix. (I feel frustrated with trying to change my voice.)

27. Ma voix me lâche en cours de conversation. (My voice "gives out" in the middle of speaking.)

8. Je suis tendue quand je parle avec les autres à cause de ma voix. (I'm tense when talking with others because of my voice.)

13. J'évite de parler en public à cause de ma voix. (I avoid speaking in public because of my voice.)

9. Ma voix devient rauque, enrouée ou voilée lorsque j'essaie de parler avec une voix féminine. (My voice gets croaky, hoarse, or husky when I try to speak in a female voice.)

6. Ma voix m'empêche de vivre comme une femme. (My voice gets in the way of me living as a woman.)

23. Ma voix me limite dans les types de métiers que je peux exercer. (My voice restricts the sort of work I do.)

17. Mes difficultés de voix limitent ma vie sociale. (My voice difficulties restrict my social life.)

25. J'ai moins envie d'aller vers les autres à cause de ma voix. $(\bigvee$ am less outgoing because of my voice.)

30. Je souffre de discrimination à cause de ma voix. (I feel discriminated against because of my voice.)

\begin{tabular}{|c|c|c|c|c|}
\hline 2.42 & 1.11 & $1-4$ & 2 & $3(30.55)$ \\
\hline 2.31 & 1.12 & $1-4$ & 2 & $1(33.33)$ \\
\hline 2.28 & 0.88 & $1-4$ & 2 & $2(41.66)$ \\
\hline 2.28 & 0.88 & $1-4$ & 2.5 & $2(50.00)$ \\
\hline 2.25 & 0.77 & $1-4$ & 1 & $2(52.77)$ \\
\hline 2.22 & 1.10 & $1-4$ & 2 & $1(36.11)$ \\
\hline 2.19 & 1.14 & $1-4$ & 1 & $1(36.11)$ \\
\hline 2.19 & 0.98 & $1-4$ & 3 & $2(44.44)$ \\
\hline 2.19 & 1.12 & $1-4$ & 2 & $1(36.11)$ \\
\hline 2.17 & 1.13 & $1-4$ & 1 & $1(38.88)$ \\
\hline 2.17 & 1.03 & $1-4$ & 2.5 & $1(33.33)$ \\
\hline 2.14 & 1.15 & $1-4$ & 2 & $1(38.88)$ \\
\hline 2.06 & 0.86 & $1-4$ & 3 & $2(44.44)$ \\
\hline 2.03 & 0.94 & $1-4$ & 2 & $2(38.88)$ \\
\hline 2.03 & 1.16 & $1-4$ & 2 & $1(47.22)$ \\
\hline 2.00 & 0.86 & $1-4$ & 1 & $2(44.44)$ \\
\hline 1.89 & 1.09 & $1-4$ & 2.5 & $1(50.00)$ \\
\hline 1.89 & 1.19 & $1-4$ & 1 & $1(58.33)$ \\
\hline 1.86 & 1.10 & $1-4$ & 2 & $1(52.77)$ \\
\hline 1.81 & 1.09 & $1-4$ & 2 & $1(58.33)$ \\
\hline 1.72 & 1.03 & $1-4$ & 3 & $1(58.33)$ \\
\hline
\end{tabular}


12. Je me sens mal à l'aise quand je parle avec des amis, des voisins ou ma famille à cause de ma voix. (I feel uncomfortable talking to friends, neighbours, and relatives because of my voice.)
14. Le son de ma voix est artificiel. (My voice sounds artificial.)

1.47

0.77

$1-4$

1

$1(66.66)$

Notes: $\mathrm{N}=36$. The original items of the TVQ ${ }^{\mathrm{MtF}}$ are in parentheses.

* (\%) Percentage of people who responded with this value.

Abbreviations: SD, standard deviation; TVQMtF, Transsexual Voice Questionnaire for Male-to-Female.

\section{INTERNAL CONSISTENCY AND RELIABILITY}

To investigate our first hypothesis, which was that repeatability and reliability measures would be similar to those obtained for the English original, we first analyzed the questionnaire's internal consistency using Cronbach alpha for both test times. Cronbach alpha is 0.97; we therefore observe that the translation of TVQ ${ }^{\mathrm{MtF}}$ has a high level of internal consistency. That means that all the items assess the same dimension, namely, voice feminization. Moreover, the average inter-item correlation (0.54) shows that items are not redundant. This result is good and shows that each item is included for a reason. Table 3A (Test) and 3B (Retest) display the correlation result for each item. All correlations are positive, ranging between 0.156 (Test)/0.192 (Retest) and 0.898 (Test)/0.916 (Retest). The lightest blue shows the weakest correlations and the darkest blue shows the strongest.

To determine the degree of homogeneity of the tool, we analyzed the correlation between each item and the global score for the test and the retest. On the test, the correlation ranged between 0.15 and 0.89 . On the retest, the correlation varied between 0.19 and 0.91 . On the test, 27 of the 30 items obtained a correlation equal to or greater than 0.60 . The score improved slightly on the retest, with 28 items out of 30 obtaining a correlation equal to or greater than 0.60 . Only item 1 "I can hardly hear myself in a noisy environment" scored 0.15 in the test and 0.19 in the retest (Figure $2 \mathrm{~A}$ and 2B).

As for test-retest reliability, the ICC had an $r=0.96(P=0.001)$, which reveals excellent stability over time.

FIGURE 2. A. Correlation matrix for the test. B. Correlation matrix for the retest.

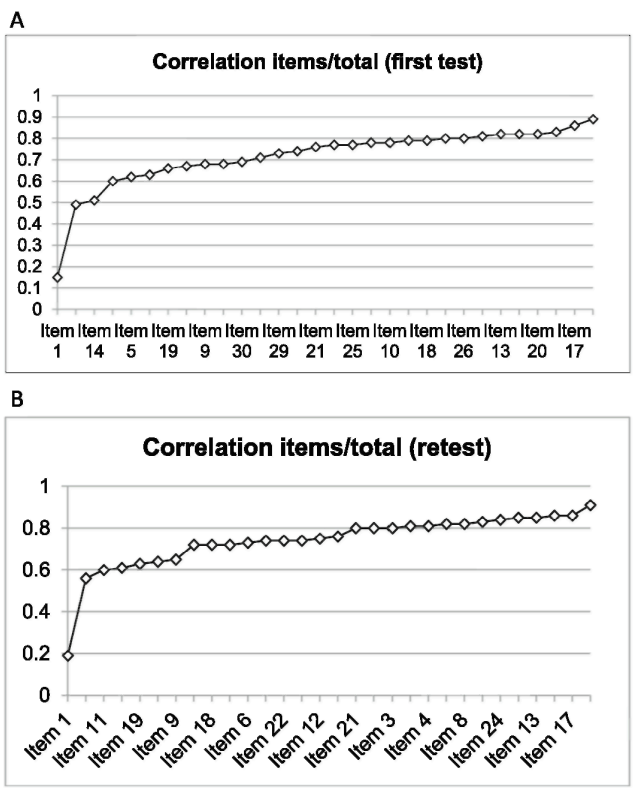




\section{TABLE 3. A. Intercorrelation Table: Test. B. Intercorrelation Table: Retest.}

A

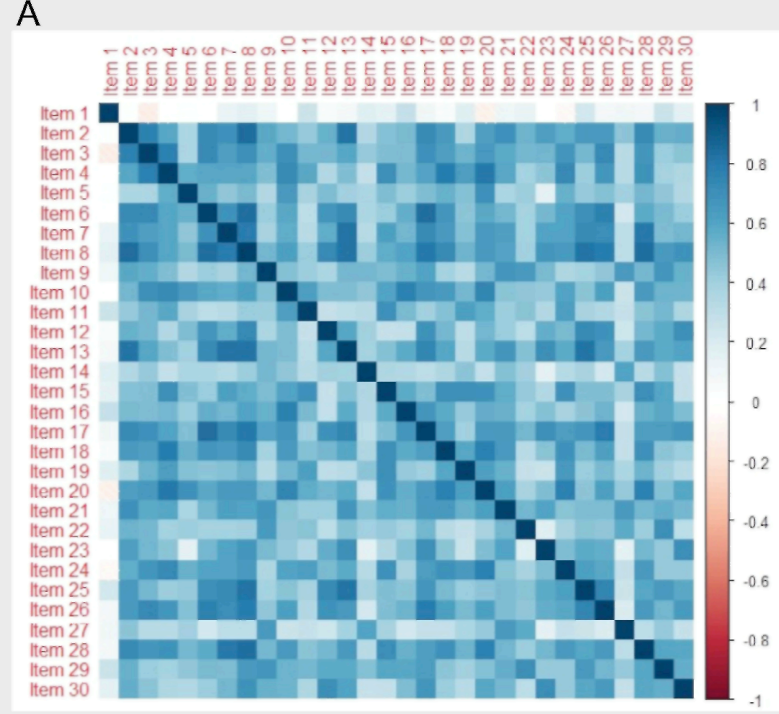

B

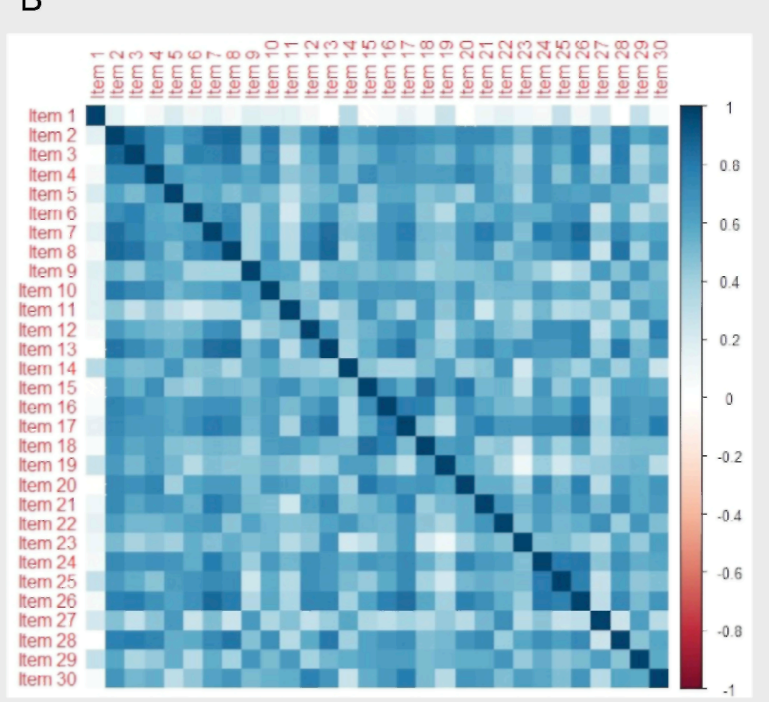

Notes: red, negative correlation; blue, positive correlation; 0, null correlation. (For interpretation of the references to color in this figure legend, the reader is referred to the Web version of this article.)

\section{VALIDITY}

Validity is assessed in three steps: the coding of the participants' written answers according to the domains established by the Dacakis et al, ${ }^{6}$ the construct validity analysis, and the concurrent validity analysis.

Determining the construct validity of a questionnaire - whether it measures what it is supposed to measure-usually involves comparing it to another scale measuring the same thing. At present, no other relevant scale exists in French. We used the same procedure that Davies and

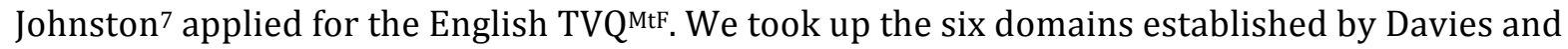

Johnston and ranked the content of our participants' written ideas in the six domains, namely, effect of voice on ease of social interaction, effect of voice on emotions, relationship between voice and gender identity, effort and concentration required to produce voice, physical aspects of voice production, and pitch. The last author of this paper (Thomas) identified 81 voice-related ideas and ranked them according to the six domains. Ideas that did not fall into these six domains were assigned to a seventh domain labeled "other." The first author (Morsomme) reclassified the 81 ideas by domain so that her classification could be compared to Thomas's. Three ideas classified in "other" were discussed and finally remained in this category. Table 4 illustrates the final ranking of ideas by domains.

The 12 ideas (14.81\%) that did not fall into the six domains are related to singing, acceptance of one's own voice, and vocal accompaniment by a coach or a vocologist.

To analyze the statistical representativeness of the ideas in the questionnaire, we measured the relationship between the frequency of participants' written ideas and their presence in the questionnaire via a chi-square test (Table 5).

We obtained a chi-square of $2.4(P=0.046)$. There is a statistical dependence between the ideas expressed by the participants and the TVQ ${ }^{\mathrm{MtF}}$ items. In addition, ideas that are not represented in the questionnaire are the ones that occur least frequently. We then decided to compare the 
items of the questionnaire to the participants' written answers. Eight of the 30 items are not expressed in the participants' written ideas.

We then ranked the written ideas of each participant according to the seven domains, as shown in Table 6.

We analyzed the correlation between the ranking of ideas by domain and their distribution within the items of the questionnaire using Spearman rank test. We did not find a significant correlation between these distributions $\left(r_{s}=0.23\right)$. The areas that are most prominent in the participants' writings are not those that are represented by the largest number of items in the questionnaire.

We concluded with the construct validity analysis by observing the level of agreement among participants concerning the degree of importance that each of them attributed to the different domains. With Friedman ANOVA, we obtained a chi-square $(22.6)=42.01(P=0.000)$. Participants did not respond in the same way to the different domains. Kendall concordance coefficient, which indicates the degree of association of participants' assessments across domains, confirms this result $(\mathrm{w}=0.20)$. Nonetheless, we compared the means two-by-two to clarify where the differences were. Figure 3 illustrates how the domains were scored.

Domain 1-the effect of voice on social interaction-is mentioned significantly more often than the others and subject to a stronger consensus among participants.

Concurrent validity consists of comparing the scores of the respondents to the TVQ ${ }^{\mathrm{MtF}}$ to the scores related to the coding of their ideas according to the domains. We observed no correlation with Spearman correlation coefficient on the test or the retest, $r_{s}=0.50(P>0.05)$. We then focused on the items that were scored 4 on the rating scale (ie, usually, always), as a score of 4 reflects a high degree of concern with the item in question. We calculated a percentage for each item that received a score of 4 and compared it to the percentage obtained for each domain. The results of Spearman coefficient on both test and retest were negative and nonsignificant $\left(r_{s}=\right.$ $0.14, r_{s}=-0.21$ ). We did not observe any agreement between the level of concern expressed with the items of the TVQ ${ }^{\mathrm{MtF}}$ and the level of concern in the participants' written responses.

\section{TABLE 4. Classification of the Participants' Written Ideas per Domain}

No. Domains Established by Dacakis et al ${ }^{6} \quad$ Ideas per Domain (\%)

\begin{tabular}{lll}
\hline 1 & $\begin{array}{l}\text { Effect of voice on ease of social } \\
\text { interaction }\end{array}$ & 26 Ideas (32.09) \\
2 & Effect of voice on emotions & 4 Ideas (4.94) \\
3 & $\begin{array}{l}\text { Relationship between voice and gender } \\
\text { identity }\end{array}$ & 16 Ideas (19.75) \\
4 & $\begin{array}{l}\text { Effort and concentration required to } \\
\text { produce voice }\end{array}$ & 6 Ideas (7.41) \\
5 & $\begin{array}{l}\text { Physical aspects of voice production } \\
6\end{array}$ & 7 Ideas (8.64) \\
7 & Pitch & 10 Ideas (12.34) \\
\hline
\end{tabular}


TABLE 5. Number of Ideas Mentioned According to Their Occurrence in the Participants' Writings and in the TVQMtF

In the questionnaire High occurrence Low occurrence

$$
(>10 \%) \quad(<10 \%)
$$

\begin{tabular}{lll}
\hline Present & 52 & 17
\end{tabular}

Absent $\quad 12$

Note: "Occurrence" refers to the number of ideas in the written answers related to the questionnaire items. Abbreviation:TVQMtF, Transsexual Voice Questionnaire for Male-to-Female.

TABLE 6. Percentage of Each Participant's Ideas in Each Domain

\begin{tabular}{|c|c|c|c|c|c|c|c|}
\hline $\mathrm{P}$ & D $1(\%)$ & D $2(\%)$ & D $3(\%)$ & D $4(\%)$ & D $5(\%)$ & D $6(\%)$ & D $7(\%)$ \\
\hline 1 & 33.33 & 0 & 0 & 0 & 33.33 & 33.33 & 0 \\
\hline 2 & 100 & 0 & 0 & 0 & 0 & 0 & 0 \\
\hline 3 & 100 & 0 & 0 & 0 & 0 & 0 & 0 \\
\hline 4 & 33.33 & 0 & 33.33 & 0 & 0 & 33.33 & 0 \\
\hline 5 & 33.33 & 0 & 33.33 & 0 & 0 & 33.33 & 0 \\
\hline 6 & 33.33 & 0 & 0 & 0 & 33.33 & 33.33 & 0 \\
\hline 7 & 33.33 & 0 & 0 & 16.66 & 16.66 & 0 & 33.33 \\
\hline 8 & 0 & 0 & 50 & 0 & 0 & 0 & 50 \\
\hline 9 & 33.33 & 0 & 33.33 & 0 & 0 & 33.33 & 0 \\
\hline 10 & 50 & 25 & 25 & 0 & 0 & 0 & 0 \\
\hline 11 & 33.33 & 0 & 0 & 0 & 33.33 & 0 & 33.33 \\
\hline 12 & 50 & 0 & 50 & 0 & 0 & 0 & 0 \\
\hline 13 & 33.33 & 0 & 33.33 & 0 & 0 & 0 & 33.33 \\
\hline 14 & 100 & 0 & 0 & 0 & 0 & 0 & 0 \\
\hline 15 & 0 & 0 & 100 & 0 & 0 & 0 & 0 \\
\hline 16 & 100 & 0 & 0 & 0 & 0 & 0 & 0 \\
\hline 17 & 0 & 0 & 0 & 0 & 0 & 100 & 0 \\
\hline 18 & 100 & 0 & 0 & 0 & 0 & 0 & 0 \\
\hline 19 & 0 & 0 & 0 & 0 & 50 & 50 & 0 \\
\hline 20 & 33.33 & 33.33 & 33.33 & 0 & 0 & 0 & 0 \\
\hline 21 & 0 & 0 & 0 & 50 & 0 & 0 & 50 \\
\hline 22 & 0 & 0 & 50 & 0 & 50 & 0 & 0 \\
\hline 23 & 0 & 0 & 0 & 0 & 0 & 0 & 0 \\
\hline 24 & 0 & 0 & 0 & 0 & 0 & 0 & 100 \\
\hline 25 & 12.5 & 25 & 25 & 12.5 & 0 & 12.5 & 12.5 \\
\hline 26 & 0 & 0 & 100 & 0 & 0 & 0 & 0 \\
\hline 27 & 50 & 0 & 0 & 50 & 0 & 0 & 0 \\
\hline 28 & 33.33 & 0 & 0 & 33.33 & 0 & 0 & 33.33 \\
\hline 29 & 50 & 0 & 50 & 0 & 0 & 0 & 0 \\
\hline 30 & 50 & 0 & 0 & 50 & 0 & 0 & 0 \\
\hline 31 & 25 & 0 & 25 & 0 & 0 & 25 & 25 \\
\hline 32 & 0 & 0 & 50 & 0 & 0 & 0 & 50 \\
\hline 33 & 0 & 0 & 0 & 0 & 0 & 0 & 0 \\
\hline 34 & 33.33 & 0 & 0 & 0 & 0 & 33.33 & 33.33 \\
\hline 35 & 50 & 0 & 0 & 0 & 50 & 0 & 0 \\
\hline 36 & 100 & 0 & 0 & 0 & 0 & 0 & 0 \\
\hline Mean & 38.35 & 2.45 & 20.34 & 6.24 & 7.84 & 11.39 & 13.35 \\
\hline SD & (33.92) & (8.08) & (27.99) & (15.29) & (16.53) & (21.69) & $(23.20)$ \\
\hline
\end{tabular}


Abbreviations: D, domain; P, participant.

FIGURE 3. Participants' scores according to domain.

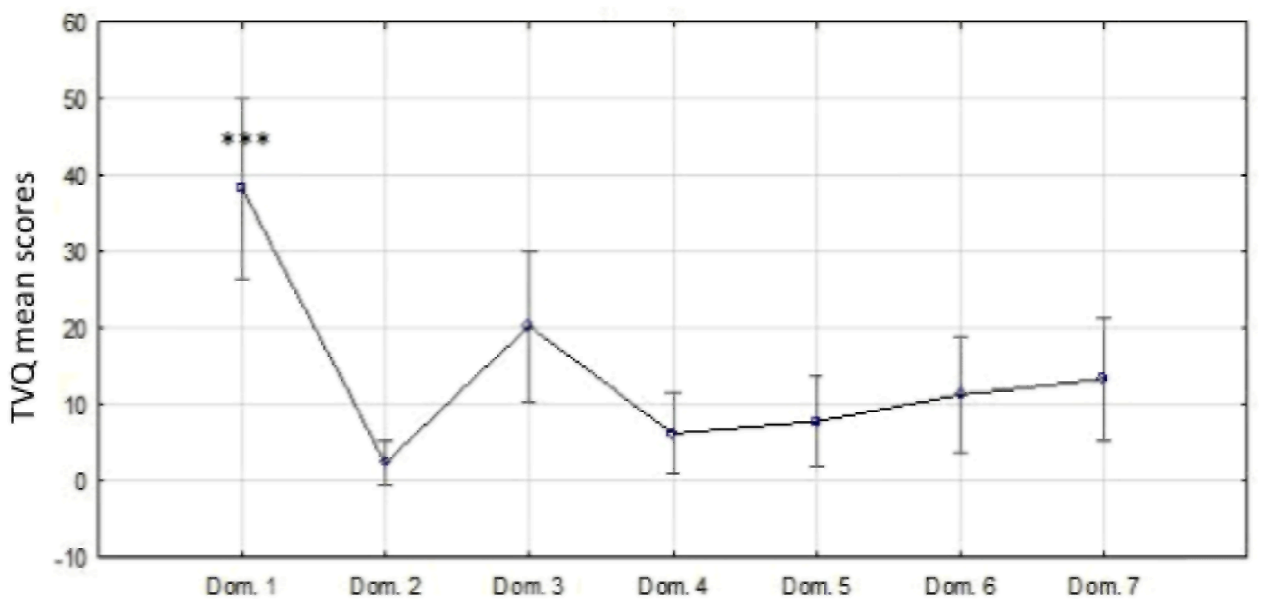

Dom, domain; Dom. 1, effect of voice on ease of social interaction; Dom. 2, effect of voice on emotions; Dom. 3, relationship between voice and gender identity; Dom. 4, effort and concentration required to produce voice:. Dom. 5, physical aspects of voice production; Dom. 6, pitch; Dom. 7, other. ${ }^{* * *}$ Significant differences between Domain 1 and the other domains. TVQ, Transsexual Voice Questionnaire.

\section{VOICE THERAPY EFFECT}

We expected participants who had received voice therapy sessions $(\mathrm{N}=18)$ or were being treated at the time of the study $(\mathrm{N}=8)$ to obtain lower scores than those who had not received voice therapy $(\mathrm{N}=10)$. We did not observe any significant difference between the three groups (one-way ANOVA, $\mathrm{F}_{(2,33)}=2.19 ; P=0.12$ ). This result could be explained by a lack of statistical power, so we wanted to verify the differences between the three subgroups, and therefore carried out a post hoc test. The results showed that participants who had completed their treatment tended to score lower than the other participants, as shown in Figure 4.

FIGURE 4. Mean TVQ ${ }^{M t F}$ scores related to voice therapy status.

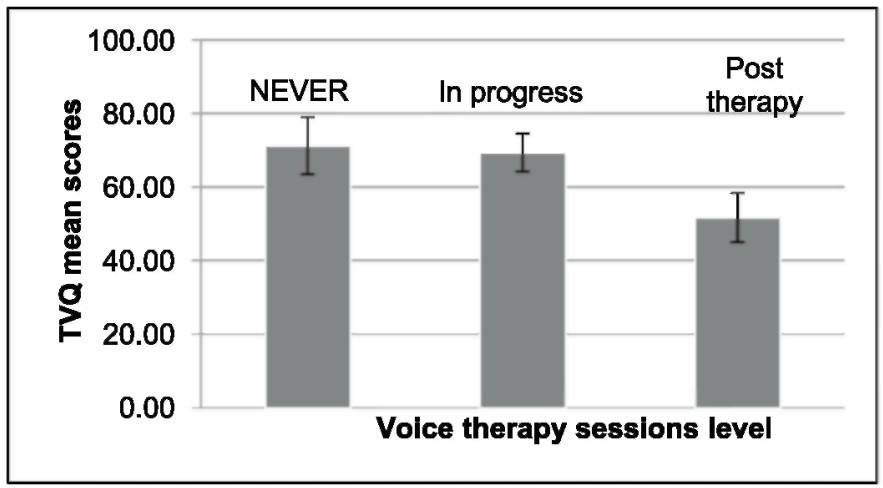

Never, no therapy session; In progress, therapy in progress during the testing; Post therapy, voice therapy sessions were finished. TVQ ${ }^{\mathrm{MTF}}$, Transsexual Voice Questionnaire for Male-to-Female. 


\section{NATIONALITY EFFECT}

We checked the possible influence of the participants' country of origin (Belgium vs. France). No difference between the two groups was observed with Student $t$ test $\left.\left(\mathrm{f}_{(3} 4\right)=-0.27 ; P=0.78\right)$.

\section{DISCUSSION}

Trans women are requesting vocal feminization more often in both Belgium and France. We need to adapt our voice evaluation techniques and include adapted questionnaires to better understand their specific needs. The TVQ ${ }^{\mathrm{MtF}}$ adapted in French will complement the existing voice assessment tools and help clinicians better establish therapeutic plans for this population. Thus, with this tool, we will be able to better integrate client and caregiver perspectives in light of evidence-based practice.

\section{TRANSLATION OF THE QUESTIONNAIRE}

We respected all the steps stipulated by the WHO.12 In particular, we worked on the choice of vocabulary to make sure it was understandable and accessible to everyone. The first step consisted in coming to grips with the original questionnaire with the help of the authors so we could respect their recommendations. The group of French-language experts involved came from three different universities located in three countries: University of Liège (Belgium), University of Marseille (France), and University of Montreal (Canada). They all shared French as a common language, with various specific features related to the country. This diversity allowed us to engage in more wide-ranging discussions regarding the adaptation of the tool into French. Likewise, making use of the skills of a translator who was unfamiliar with the subject and whose native language was English allowed for a faithful back-translation of the questionnaire into English.

\section{RECRUITMENT OF PARTICIPANTS}

It proved difficult to recruit participants despite our participation in meetings of LGBT groups. In the end, social media and speech therapists or speech language pathologists specializing in voice feminization enabled us to recruit the participants. Thirty-six participants completed the questionnaire twice. The sample size is reasonable when one considers that the proportion of transgender women ranges between 1:100,000 and 1:1,000, according to Garcia et al.14 Moreover, the authors of the TVQ ${ }^{\mathrm{MtF}}$ investigated test-retest reliability with a group of 35 participants; our results are comparable to theirs. The main difference between their group and ours relates to the source of participants: Dacakis et al recruited participants essentially through speech therapy consultations, ${ }^{6}$ whereas our participants were recruited via social media, speech therapists, and LGBT associations. We did not meet the participants; the trans women in our study did not interact with any members of our team while filling in the questionnaire. Regarding the open-ended questions concerning their spontaneous written ideas, we were not able to take the discussion further, as Davies and Johnston did in their interviews. ${ }^{7}$ Our validity analysis is based on the written ideas of all the participants, whereas Davies and Johnston's analysis is based on the interviews with five trans women by a graduate student trained in ethnographic methodology.

The merits of presenting the questionnaire online are debatable. The advantage is that it allowed us to include 25 participants from France in the group. Nevertheless, we think that, because it 
was an online survey, participants elaborated less on their responses to the open-ended questions than they would have done in person. Indeed, we calculated a mean of 2.4 ideas expressed per person, which is low compared to the responses from the participants in the Davies and Johnston study, ${ }^{7}$ who generated as many as 240 ideas in the interview set. Nevertheless, their interviews were not with all participants but with only five. Their semistructured interviews were conducted by a student specializing in ethnographic methodology, who kept the conversation going in order to gather as much data as possible; this method can be critiqued in terms of the structuring of the discourse and the representativeness of the population. No doubt, oral interviews would have produced more details and more ideas, ${ }^{15,16}$ as writing constrains respondents to certain forms of expression and requires them to pay more attention to formulation and spelling, for example.

\section{INTERNAL CONSISTENCY AND TEST-RETEST RELIABILITY}

We corroborated the results of Dacakis et al6: Cronbach alpha for the English questionnaire was 0.96 for the test and 0.97 for the retest. For the French version, we obtained 0.97 for the test and retest. In other words, less than $10 \%$ of the variance in scores can be attributed to errors in constructing the questionnaire. As for the questionnaire's homogeneity, we again replicated the results for the original questionnaire, 6 as 27 of the 30 items of the French questionnaire obtained a correlation equal to or greater than 0.60 , whereas 24 of the 30 items in the English questionnaire met this condition. Our test-retest reliability was excellent, with a correlation coefficient of 0.966 , which was very similar to that of the English TVQMtF $(0.979)$. The properties of the French TVQ ${ }^{\mathrm{MtF}}$ are therefore solid and robust.

The validity analysis was based on the coding of the ideas expressed in the participants' responses to open-ended questions. As we collected considerably fewer ideas than Davies and Johnston, ${ }^{7}$ we were unable to replicate their results owing to a lack of statistical power.

Validity

Concerning construct validity, our results did not differ from those for the English TVQ ${ }^{\mathrm{MtF}}$. According to the coding of the answers to the open-ended questions, participants mentioned six domains; $8.64 \%$ of the ideas mentioned concerned the role of speech therapy in relation to their voice satisfaction, compared to $10.7 \%$ for respondents to the English TVQ ${ }^{\mathrm{MtF}}$. Like the original authors, we noted that the most predominant domains in the participants' stories are not the dominant ones in the questionnaire. For example, the "effect of voice on emotions" domain was not mentioned much by the trans women in their written ideas (4.94\% of ideas); however, six items in the questionnaire concerned this domain. On the other hand, the "pitch" domain was mentioned more often by the trans women $(12.34 \%$ of ideas) but only addressed in four items in the questionnaire. To sum up, we can say that overall the items retained in the TVQ ${ }^{\mathrm{MtF}}$ correspond to the ideas most often mentioned by the participants (which is also true of our questionnaire), which gives it good representativeness. Concerning concurrent validity, unfortunately, we were unable to replicate Davies and Johnston's results. ${ }^{7}$ In all likelihood, the written modality plays an important role in the lack of correlation between TVQMtF scores and the contents of the spontaneous stories. As explained above, we did not meet the trans women. They filled in the questionnaire and answered the open-ended questions via a web platform. In addition, none of us asked the participants further questions to try to increase the number of ideas that they expressed on the topic of voice. Davies and Johnston collected 240 ideas, compared to 84 in our study. Moreover, we did the entire analysis (internal consistency, 
repeatability, and validity analysis) with the same group of trans women in a single study. For the original TVQ ${ }^{\mathrm{MtF}}$, two studies were conducted. The first ${ }^{6}$ concerned the internal consistency and repeatability of the tool, and the second ${ }^{7}$ the validity analysis. So the groups of participants were not the same in the two studies. For the validity analysis, Davies and Johnston 7 recruited five trans women. All the ideas related to the voice come from these interviews with the five participants, whereas in our study all the participants answered the open-ended questions related to the impact of their voice in daily life.

\section{TVQMTF SCORES}

We noted that the functional impact of the voice was mentioned significantly more often than the psychosocial consequences. According to Michel,17 many transgender women find it difficult to adapt to the social world around them. The scores obtained on the French TVQ ${ }^{\mathrm{MtF}}$ did not corroborate that observation. Participants' voices probably did affect their integration into society but less significantly than suggested. This in no way negates the fact that "vocal passing" in public remains a goal of therapy. The fact that the functional impact is more of a concern for our participants shows that they have to work hard, both technically and strategically, to present a female voice.

\section{VOICE THERAPY EFFECT}

Participants who had gone through voice therapy tended to score lower on the questionnaire than those who had not. A larger sample of participants is necessary to confirm this observation. Nevertheless, it backs up the importance of voice therapy treatment for voice feminization.

\section{CONCLUSION}

We decided to translate and adapt into French the Transsexual Voice Questionnaire for Male to Female. ${ }^{6}$ On the one hand, in choosing this scale, we found the specific nature of the TVQ ${ }^{\mathrm{MtF}}$ items-that is, items designed for people seeking voice feminization-and its rigorous construction to be important. On the other hand, the inappropriate use of the VHI ${ }^{10}$ (in the French-speaking area of Belgium) in the context of requests for voice feminization encouraged us to meet the clinical need for an appropriate tool to use in the field.

The purpose of this study was also to do a psychometric evaluation of the French version on the basis of statistic analyses identical to those used for the English version. The reliability and repeatability measures are very good, corroborating those for the English TVQ ${ }^{\mathrm{MtF}}$. The construct validity measures show that the questionnaire items relate to the six domains mentioned by participants in their written responses. Concurrent validity could not be analyzed owing to the lack of sufficiently detailed stories.

Participants who have completed voice therapy tend to score lower on questionnaire items than those who have not received voice feminization treatment. Thus, speech therapy appears to play a substantial role in this kind of treatment.

\section{Acknowledgments}

We thank Ingrid Verduyckt for her help in translating the questionnaire, Alice Cameron for translating the questionnaire into English twice, Vincent Didone for supervising the statistics, and finally all the participants who gave their time to complete the questionnaire. 


\section{APPENDIX}

The Transsexual Voice Questionnaire (TVQ ${ }^{\mathrm{MtF}}$ in French) is freely available for clinical and research purposes either from the first author or at www.shelaghdavies.com.

\section{REFERENCES}

1. Holmberg EB, Oates J, Dacakis G, et al. Phonetograms, aerodynamic measurements, selfevaluations, and auditory perceptual ratings of male-to-female transsexual voice. J Voice. 2010;24:511-522.

2. Morsomme D, Remade A. Féminiser la voix. In: Klein-Dallant C, éd. De La Voix Parlée Au Chant: Bilans, Reeducations, Pathologies De La Voix Parlée et Chantée. Paris: Klein-Dallant; 2016:327340 .

3. T'Sjoen G, Moerman M, Van Borsel J, et al. Impact of voice in transsexuals. Int J Transgender. 2006;9:1-7.

4. Dejonckere PH, Bradley P, Clémente $\mathrm{P}$, et al. A basic protocol for functional assessment of voice pathology, especially for investigating the efficacy of (phonosurgical) treatments and evaluating new assessment techniques. Guideline elaborated by the Committee on Phoniatrics of the European Laryngological Society (ELS). Eur Arch Otorhinolaryngol. 2001;258:77-82.

5. Pasricha N, Dacakis G, Oates J. Communicative satisfaction of male-to-female transsexuals. Logoped Phoniatr Vocol. 2008;33:25-34.

6. Dacakis G, Davies S, Oates J, et al. Development and preliminary evaluation of the Transsexual Voice Questionnaire for Male-to-Female Transsexuals. J Voice. 2013;27:312-320.

7. Davies SM, Johnston JR. Exploring the validity of the transsexual voice questionnaire for maleto-female transsexuals. Can J Speech Lang Pathol Audiol. 2015;39:40-51.

8. Dacakis G, Oates JM, Douglas JM. Exploring the validity of the transsexual voice questionnaire (male-to-female): do TVQMtF scores differentiate between MtF women who have had gender reassignment surgery and those who have not? Int J Transgender. 2016;17:124-130.

9. Davies SM. Transsexual Voice Questionnaire (Male to Female). Available at: http://www.shelaghdavies.com/questionnaire/questionnaire.html.

10. Jacobson BH, Johnson A, Grywalski C, et al. The Voice Handicap Index (Vffl): development and validation. Am J Speech Lang Pathol. 1997;6:66-69.

11. De Bodt MS, Jacobson B, Musschoot S, et al. De Voice Handicap Index. Een instrument voor het kwantificeren van de psychosociale consequenties van stemstoornissen. Logopedie. 2000;13:29-33.

12. World Health Organization. Process of translation and adaptation of instruments. 2017. Available at: http://www.who.int/substance_abuse/ research_tools/translation/en/. Accessed January 15, 2016.

13. De Bodt MS, Wuyts FL, Van de Heyning PH, et al. Test-retest study of the GRBAS scale: influence of experience and professional background on perceptual rating of voice quality. J Voice. 1997;11:74-80. 
14. Garcia D, Gross P, Baeriswyl M, et al. De la transsexualité à la dysphorie de genre: recommandations de conseil et de traitement pour les personnes trans. Forum Med Suisse. 2014;14:382-387.

15. Ganassali S. Enquêtes et analyse de données avec Sphinx. France, Paris: Pearson Education; 2014.

16. Fraisse P, Breyton M. Comparaison entre les langages oral et écrit. Annee Psychol. 1959;59:61-71.

17. Michel A. Le transsexuel: quel devenir? Ann Med Psychol. 2001;159:347-358. 